\title{
Peter Baker: 'It's wrong to expect women to bear the sole burden of HPV vaccination in order to protect not only themselves, but also men'
}

Interview by Adrian O'Dowd

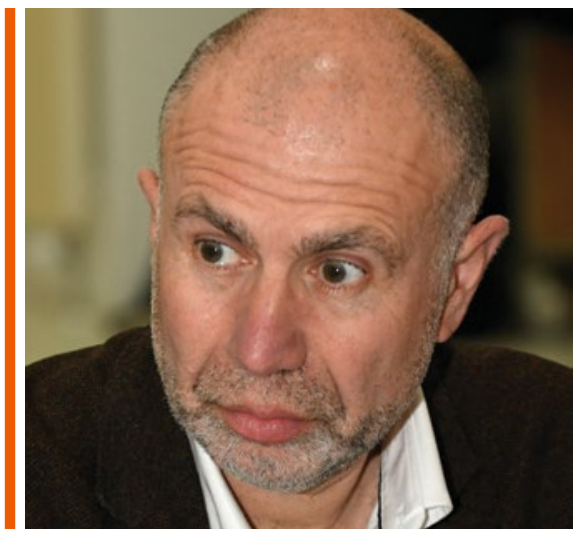

\section{Why was the HPV Action campaign group set up?}

The initiative came from Jamie Rae, chief executive of the Throat Cancer Foundation, and Tristan Almada, a founder of the HPV and Anal Cancer Foundation, who, in 2013, realised that action was needed to bring about gender-neutral HPV vaccination. I had been Chief Executive at the Men's Health Forum (Great Britain) and was by then Director of Global Action on Men's Health. We met and discussed this and decided to set up what became HPV Action.

This followed the JCVI [Joint Committee on Vaccination and Immunisation - the Government's vaccination advisory committee] beginning its assessment of whether boys should also be vaccinated in 2013. HPV Action was officially launched in 2014.

\section{Why is it so important to extend the HPV vaccination programme to boys? Several reasons. We couldn't rely on the vaccination of girls to protect males even if the vaccination of girls was $100 \%$ - which it isn't - because some men have sex with men and people move around the world and have sexual contact with people from other}

Peter Baker is Campaign Director for HPV Action, a campaigning partnership of 51 patient and professional organisations seeking gender-neutral vaccination for the human papilloma virus (HPV) that can cause lifethreatening diseases including oral cancers. The vaccination programme for teenage girls is being extended to boys from this September. countries, some of which do not have a HPV vaccination programme at all or one that doesn't reach that many women. In France, for example, only $25 \%$ of girls receive the HPV vaccine.

Vaccinating boys protects girls who haven't been vaccinated and there is a direct benefit to men.

There is also an ethical argument here - if the disease affects both sexes, then both sexes should be protected. It's wrong to expect women to bear the sole burden of vaccination in order to protect not only themselves, but also men.

\section{Why did it take so long to convince the government?}

It was about cost, primarily, and the JCVI having a very high bar for cost effectiveness. It took so long partly because the government did not allocate enough resource into looking at the issues in a timely way.

They kept putting back the deadline that they set themselves - which was originally 2015 but was put back to 2017 and then the decision wasn't made until 2018. They kept on saying Public Health England (PHE) needed more time for its modelling work and they couldn't get it done in time.
Also, their model was flawed. They were feeding inaccurate data into the model, for example they consistently underestimated the proportion of oropharyngeal cancers caused by HPV. They were also just looking at cost-effectiveness and not at the wider issues of public health, equity and ethics.

The JCVI produced an interim report in 2017 - based on the wrong data - and it said it wasn't cost effective to vaccinate boys. We thought at that point they were not going to change their minds but thankfully they looked again at the data and modelling. They were also put under a lot of political, media and legal pressure - there was a very real threat of a legal challenge.

\section{Was there a turning point at which you} thought this will happen?

There were several turning points. From a political point of view, we put together a group of MPs from all parties who thought gender-neutral HPV vaccination was the right thing to do. There was a Westminster Hall debate in Parliament in 2018 a month before the JCVI had its final meeting on this. That was hugely significant and timely.

There was also a lot of media coverage. What was particularly helpful in the last 
six months was that the Mail on Sunday picked this up and adopted it as a campaign, running a series of articles looking at different issues with a consistent message that boys should be vaccinated.

Finally, the Throat Cancer Foundation - one of our members - took the first steps towards a judicial review on the ground that not vaccinating boys constituted sex discrimination. The charity successfully used crowdfunding to engage a leading firm of solicitors who obtained a legal opinion from a leading QC who specialises in human rights and equality issues.

That was a great pressure on the JCVI and the Department of Health \& Social Care and they were seriously worried that if this came to judicial review, they would lose.

\section{Was it important to get the support of various organisations, including the BDA and BMA?}

Yes. We had 51 organisations united behind the call for vaccinating boys. What was brilliant was that they came from a wide range of backgrounds - those with a particular interest in oral health but also sexual health organisations, cancer, public health and those with a wider set of interests.

In addition, many of them, including the BDA, did their own campaigning around the issue, which added hugely to what we were able to achieve.

We were very much supported by these complementary activities of a large number of our individual members. With the BDA and BMA, we did a survey of GPs and dentists which found that $95 \%$ of GPs and dentists would have their own sons vaccinated. That was a very powerful statement which generated a lot of media coverage.

\section{Is everything in place for the extended vaccination campaign to begin in September as children go back to school?}

Yes, as far as we know. Material has been sent out by PHE to school nurses and others. The vaccine supply is in place so there's no reason that it shouldn't start. Obviously, it's not going to be perfect straight away and we don't expect the rate of boys to be as high as it is for girls in the first year but we think everything is in place to have a strong start. There are also parallel plans in place for the devolved administrations. It doesn't mean that all boys will be vaccinated from September but they should all be offered their first vaccination in this coming school year.

\section{Do you think boys will be keen to} participate or will there be resistance?

The thing that concerns us is the information that is being provided to boys and their parents. PHE has decided to produce gender neutral information on HPV, aimed at both boys and girls. Because this is new, we think that an extra effort should have been made to target boys and their parents specifically. Boys will need to be clear about what the benefits are for them. If they think it's just something to help girls, they might be somewhat reluctant -although I hope not - to get it.

\section{Why it is important to have a catch-up programme for boys which parallels that available for girls?}

We want to see a catch-up vaccination programme for boys - those boys [aged up to 18] that have missed out while the JCVI failed to make a decision for all those years - because there is an opportunity, while boys are still at school, to reach them relatively easily.

The argument that the government has put forward for not vaccinating older boys does not make any sense. They have been saying that it is not necessary to vaccinate these boys because they are at less risk because of the display information about it in their practices in terms of leaflets and posters. They can help to reinforce the message that this is an important thing to do.

\section{What do you think the impact of the} extended vaccination campaign will be?

What we will see in the short term is a further reduction in the incidence of genital warts and in the longer term, a greater reduction in cancer rates. There should be an impact on cervical cancer in women and all the cancers that affect both sexes such as anal cancer and oral cancer. It will take around 50 years before we see an impact in some of these areas, but that will happen.

\section{How much is the extension of the vaccination programme going to cost?}

We don't know because the vaccine price is commercially confidential. However, we have estimated it would cost at most $£ 20$ million to bring boys into the programme in the UK.

\section{What is the future for HPV Action now?}

We are going to monitor implementation of the gender-neutral programme and we will continue to raise the issue of a catch-up programme. If there are problems with the implementation, we will press the government to sort that out.

Currently, less than half of countries in the

\section{'With the BDA and BMA, we did a survey of GPs and dentists which found that $95 \%$ of GPs and dentists would have their own sons vaccinated. That was a very powerful statement which generated a lot of media coverage.'}

girls' vaccination programme.

But the older boys are at exactly the same risk as the 12- to 13-year-old boys who are being offered a vaccine. It therefore surely makes sense to vaccinate the older boys as well.

We have raised this with the government several times and been given a clear no, but we are not going to give up pushing for it.

\section{Are there ways that dentists can help with the programme extension?}

Dentists can't offer the vaccine but they can certainly remind boys and their parents that they should get vaccinated and stress the importance of it. They could perhaps
European Union have a gender neutral HPV vaccination programme. We are engaged in discussions with colleagues in Europe to see whether we can begin a Europe-wide campaign for gender neutral vaccination. The European Cancer Organisation (ECCO) recently had its cancer summit meeting in Brussels and we spoke at that about our work in the UK.

We hope that campaign might also look at screening and early diagnosis of HPVrelated diseases. We want to take what we've learned about how to campaign on these issues in the UK and get some of those ideas and approaches adopted more widely in Europe. 